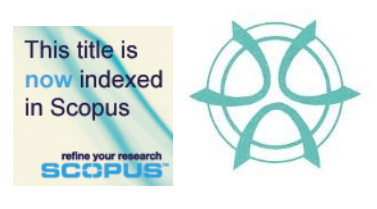

PLANNING MALAYSIA:

Journal of the Malaysian Institute of Planners

VOLUME 17 ISSUE 1 (2019), Page 280 - 291

\title{
THE SAFE AND NURTURING LIVING ENVIRONMENT FOR URBAN CHILDREN
}

\author{
Mariatul Liza Meor Gheda ${ }^{1}$ \& Habizah Sheikh Ilmi $^{2}$ \\ ${ }^{I}$ Faculty of Design and Architecture \\ UNIVERSITI PUTRA MALAYSIA \\ ${ }^{2}$ School of Architecture, Building and Design \\ TAYLOR'S UNIVERSITY
}

\begin{abstract}
As an inheritor of the nation's future, children should be given the assurance to live and grow in the best possible environment. It is our dream that they would become a persevering, progressive and as well as a well-behaved generation both physically and mentally. In order to achieve that, it is important for the children to be provided with a safe and secure environment to grow up. The research objective is to identify the characteristics of safe and nurturing environment for urban children. The data were collected through focus group interviews with children age 10 and 11 in a research participatory workshop in Sekolah Kebangsaan Seksyen 7, Shah Alam. There were 28 students involved in the workshop. The results indicated the two significant characteristics that promote a safe and nurturing environment for children to roam freely are positive parents and community support.
\end{abstract}

Keyword: Children, safety, nurturing, living environment 
PLANNING MALAYSIA

Journal of the Malaysia Institute of Planners (2019)

\section{INTRODUCTION}

Today, reading or listening about crime against a child in the radio, newspaper, television or even online websites have become very common. Statistics from the Bukit Aman Sexual, Women and Children Investigation Division disclosed that there were 3,223 missing children under the age of 18 from the year 2008 until April 2011. However, only 1,708 cases were resolved. In 2015, 1,782 cases of missing children were reported and as in January 2016, 140 cases have been reported (The Star, 2016).

The problem of paedophiles has also become more apparent in the recent years in Malaysia. As mentioned by Marret, Satar, and Ismail (2013), the police have highlighted that the cases of missing children may be connected to human trafficking, which in most cases involve the sexual abuse by paedophiles, trading for slavery, forced child labour or money-making sexual works. Hence, parents nowadays are more hesitant to let their children to roam free and play outdoors, as they may be exposed to various hazards such as accidents, the acts and bad intentions of other individuals.

This research seeks to address the issue with a particular focus on safety and nurturing environment for urban children and to have a deep understanding of children's outlook and actions on the issues involved. This study will be a significant endeavour in the literacy of children's environment in the context of urban neighbourhood.

\section{LITERATURE REVIEW}

Over a billion kids are experiencing their childhood life in urban areas today, and the number keeps on increasing in the coming years. It is almost two decades now since UNICEF and the United Nations Human Settlements Program together propelled the Child-Friendly Cities Initiative including progressive approaches and systems to address the requirements of kids in urban communities. However, numerous difficulties remain. Growing Up in Cities (GUIC) is a program that involves children in evaluating their urban environments and planning how to improve the conditions of their lives (Chawla, 2002). With the fundamental goal of influencing public policies through the inclusion of children's perspectives, it seeks to build broad alliances of committed people in taking action on children's behalf in community-based and non-government organizations and across different sectors of government.

Nowadays, children's voice in determining the direction or concept of urban planning is becoming more and more important, and this can be exemplified by Malone (2013) through a project in Sydney. This exercise should be conducted more often in Malaysia in response to the needs and aspirations as outlined in the Vision 2020, i.e. what we build today, will be inhabited by today's younger generation in the future. To support this initiative into the real practice project, United Nations Child Friendly City International Secretariat was 
Mariatul Liza Meor Gheda \& Habizah Sheikh Ilmi

The Safe and Nurturing Living Environment for Urban Children

established by UNICEF in Florence (Riggio, 2002). Furthermore, other initiatives comprise of the introduction of school gardens, community gardens (Armstrong, 2000), lower speed limits, traffic calming (Pucher \& Dijkstra, 2003), walking school buses and safe routes to school campaigns (Watson \& Dannenberg, 2008). In supporting these reversing trends, Gleeson and Sipe (2006) supported the child friendly cities and Capon and Blakely (2008) strengthened them as 'healthy cities'. Furthermore, in 2010, the New York City Streets Renaissance Campaign has been organized to reclaim streets as places to play for children (Kaboom, 2010).

Environmental child-friendliness might be threatened by shrinking open spaces, increasing traffic levels and limited independent mobility due in part to social aspects such as adults' safety fears (Bjorklid \& Nordstrom, 2007). The world is currently heading to the trend of children growing up within the confines of the four walls of their homes, rather than being adventurous outdoors. This trend is particularly popular in the Western countries (Skar \& Krogh, 2009). As this is considered as very unhealthy, actions must be taken by those who are responsible and have the power to stop this from taking a worse turn (Bell, Wilson \& Liu, 2003; McAllister, Lewis \& Murphy, 2012). Most importantly, the inclusion of children's views in the planning and decision making is deemed necessary (Elsley, 2004; Bjorklid \& Nordstrom, 2012).

Foster et al. (2015) identified the factors that shape parents' perception in fear of stranger that their child might be approached, taken or hurt by stranger. In this framework, the attributes that worsen or ease parents' concerns on their children's safety mainly focused on fear of stranger harm and perceived risk from stranger. Neighbourhood design also plays a role in promoting community safety and might impacting parental fear. Jacobs (1961) wrote that a well-used city street is apt to be a safe street and to achieve this function, it requires a substantial quantity of stores and public spaces sprinkled along the sidewalks (Jacobs, 1961). This mix of local destinations can attract more people to the neighbourhood which increases natural surveillance and the additional 'eyes on the street' are thought to help minimize crime and fear of crime (Jacobs, 1961). Some neighbourhoods has been designed to be integrated with the shopping precincts, making them less of a possible crime setting (Foster, Giles-Corti \& Knuiman, 2010). More often than not, strangers are welcome here as they offer the natural surveillance into the area (Hillier, 2004). Numerous studies suggested that the presence of other people can limit fear of crime (Jorgensen, Ellis \& Ruddell, 2012; Maruthaveeran \& Van Den Bosch, 2014) although any benefit may depend on whether these 'others' are viewed as legitimate users of the space (Day, 1999).

Paradoxically, parents desire to keep their children safe from harm can have unintended negative consequences for children's physical and psychological health (Carver, Timperio \& Crawford, 2008). Parents and children's concerns about 
PLANNING MALAYSIA

Journal of the Malaysia Institute of Planners (2019)

traffic are well founded. Younger children appear to be more at risk of traffic injury than older children.

As children aged and become more mobile, well-connected streets are associated with greater mobility. In turn, this provides children the opportunity to acquire the basic skills to interact with and move through their neighborhood. Children were given the chance to solve problem, manage risks, make judgements in different traffic situations (such as judge traffic speed, interpret traffic signs and cross roads), explore their surroundings and improve their spatial and wayfinding abilities (such as distance estimation, locating north, identifying landmarks and spatial referencing skills) (Rissotto \& Tonucci, 2002). These skills are vital for children's healthy cognitive development and are required to build confidence and competence to safely interact with their environments (Rissotto $\&$ Tonucci, 2002). However, well-connected streets are often characterized by high traffic exposure as cars and pedestrians may use the same routes.

\section{METHODOLOGY}

This research has resorted to use the guiding method concept by taking into consideration the theories, indicators, concepts, models and any research findings from previous research to guide in the undertaking of the whole research process. Apart from that, the research data were obtained through a qualitative method, in exploring children's view in order to identify the barriers of children's outdoor play in urban neighbourhood. The empirical data for research design gathered via focus group interviews from the Child Friendly Neigbourhood Environment (CFNE) Workshop in Sekolah Kebangsaan Seksyen 7, Shah Alam. 28 children age 10 and 11 were selected as the respondents of this research.

This research addresses the interdisciplinary nature of research involving children and how the methods of research can meet children's 'human sense'. According to Robinson (1986), most of children aged11 years old and older are fully able to articulate their perceptions, opinions, beliefs; and with a relatively little adaptation, thus, a survey designed for adults can be used with adolescents. The participants involved were those children living in Zone 3, Shah Alam and has no speech difficulties. Based on the academic performance, these participants were among the average to excellent achievers.

Donaldson (1978) emphasized that the design of the task for children should be possible to reveal their true competencies. The tasks must meet 'human sense' to children. In the workshop, the author and the facilitators have demonstrated that a carefully crafted investigation can offer important insights about children's capacities. Thus, each activity has been planned and designed to be suitable to the participants.

Drawing was used in the workshop as it is regarded as a universal language and it offers children a valuable release for emotion, which may not be verbalized, and it serves as a means of communication. When drawing is used as 
Mariatul Liza Meor Gheda \& Habizah Sheikh Ilmi

The Safe and Nurturing Living Environment for Urban Children

a tool for communication, children are able to express themselves and make meaning out of the world around them. Using drawing as a means of communication helps the process of making ideas, thoughts, and feelings available to others (Adams, 2006).

\section{RESULTS AND DISCUSSIONS}

A remarkable decline in the level of children's freedom to explore their own neighbourhood independently has occurred over the last few decades in Malaysia. Analysis of this research identified the importance of children's freedom of movement with the combination of diverse environmental affordances to facilitate play which is fundamentally important in a child friendly environment. These findings are congruent with the findings from a research by Hart (1979) in supporting freedom of children movement. He stated that the independent mobility is not only important for the children, but it also gives value for their parents and other adults who are responsible for them, for the wider environment and for the strength and vitality of local neighbourhood communities. As stated by Freeman and Tranter (2011), the level of children's independent mobility is an indicator of the success and resilience of a city.

Extra traffic adds to parental concern on safety and reduces the number of children allowed to walk around the local streets. Most of the participants of participatory workshop noticed, since most people have chosen to drive rather than to walk or cycle, the streets have become lonely, deserted and are seen as dangerous, as there was no one around to provide passive surveillance for them. As expressed by BA5, everyday, he goes to school with his father and came home with his mother. Even though the distance of his house was less than one kilometre from school, his parents were not confident to let him walk or ride independently.

To understand how children felt about their neighbourhood, the workshop facilitator has asked what they liked and disliked about their neighbourhood, their most favourite and least favourite places, as well as the places they identified as child-specific areas in the neighbourhood. They were asked to identify any safety issues that exist in their neighbourhood environment.

Figure 1 shows the neighbourhood's map as drawn by GA7. The neighbourhood lookscomplete with a playground, futsal's court, surau and security guard post. However, when researcher asked about how she felt about her neighbourhood, the girl looked unhappy. She said:

Even though there is a playground near my house, I seldom go there...because I don't have friends here. Usually, it is only the smaller kids who went to the playground, as small as seven years and below. I love to play in natural space. (Translated by the author) 
PLANNING MALAYSIA

Journal of the Malaysia Institute of Planners (2019)

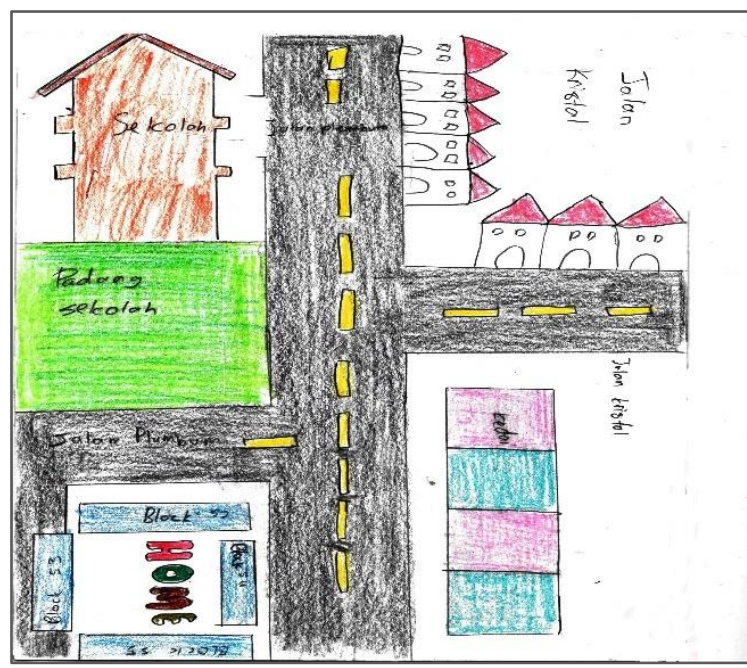

Figure 1: The neighbourhood map as drawn by GA7

The neighbourhood map done by GA4 (Figure 2) shows that a playground was provided in her neighbourhood. She also drew a gate to access the playground, as well as some playing equipment. Based on the map, the researcher asked her about the condition of the playground. In response to that, GA4 explained:

There is a playground near my housing area. However, it is always empty and seems deserted. The location which is at the end of the neighbourhood makes it even more hostile. There seems to be no attraction for children to go to the playground. Much playground equipment is broken and the grasses are left to grow. There was once an incident where a child has seen a snake in that area. (Translated by the author)

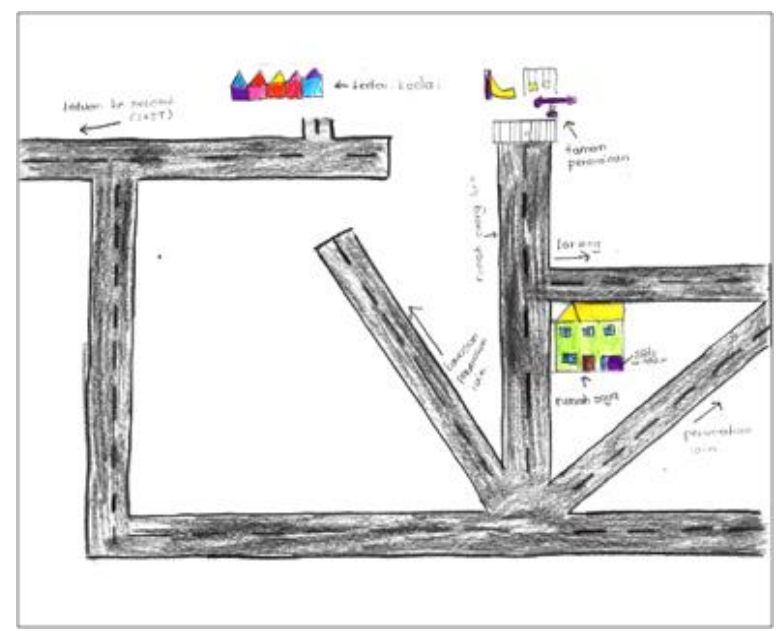

Figure 2: The neighbourhood map as drawn by GA4 
Mariatul Liza Meor Gheda \& Habizah Sheikh Ilmi

The Safe and Nurturing Living Environment for Urban Children

In Zone 3, the increasing number of residential, industrial and commercial areas can lead to the loss of open spaces and children are likely to be acutely affected by this. As illustrated in Figure 3, GA5 was staying in an apartment and the apartment was surrounded by a school, a mosque and commercial buildings. She felt that there are no space for nurturing environment within the vicinity of her flat. If she wants to go to the green space, she needs to walk with her parents because crossing the road on her own would be dangerous. She would prefer it very much if the play space or green space is located just below her apartment or that every floor of the flat is provided with one green space for the children.

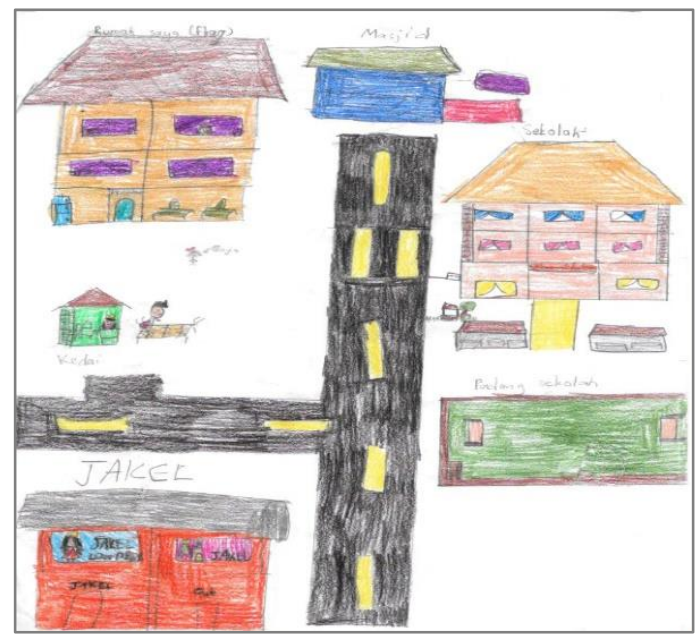

Figure 3: The neighbourhood map as drawn by GA5

The neighbourhood becomes the story about what they do and play. The neighbourhood has been going through changes by means of the children's narratives. Since the activities, experiences and narratives within the neighbourhood are in some ways rather different from those of the adults, children's perceptions and narratives about the neighbourhood will not be identical to those of the adults.

From the children's comments, it is evident that it is difficult to attain excitement and be imaginative in their neighbourhood because they were often challenged and provoked by the sense of order, neatness, control and safety by the adults. This is also due to the fact that the potential for excitement and imagination at accessible playgrounds differs at a great deal from one neighbourhood to the next. As opposed to GA4, even though she adores badminton, she does not get the opportunity to play frequently. The space to play was limited and was normally occupied by adults. 
PLANNING MALAYSIA

Journal of the Malaysia Institute of Planners (2019)

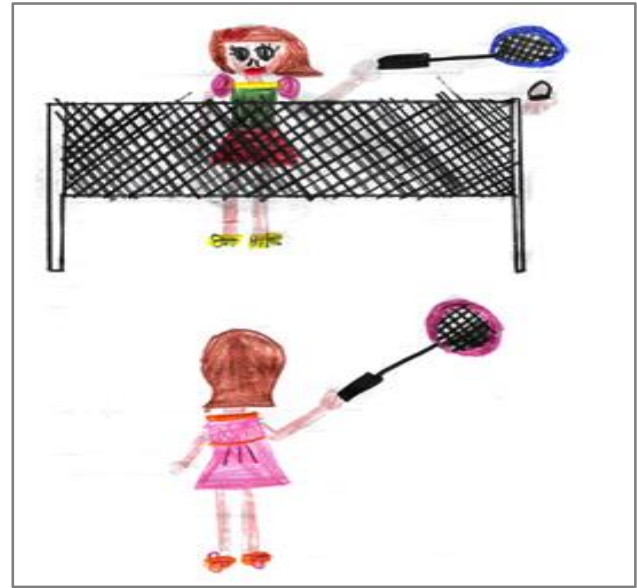

Figure 4: Drawn by GA4

In this research, the two main characteristics that promote a safe and nurturing environment for children to roam around with freedom are positive parents and community support.

\section{Positive Parents}

Parents' perception of safety has a close relationship with their fear of crime towards their children. Sutton (2008) indicated that societal fears have also impacted children's use of outdoors - with concern over crime and children's safety in public space linked with a decreasing amount of time spent by children in the outdoors. The issue of stranger danger seems to be a concern here even though the evidence illustrated that there are little likelihood for stranger danger encounters. This may just be a residue of a cultural fear of strangers pervading Malaysian media.

When discussed about these strangers, BA8 mentioned that:

I'm staying in the flats... The playground and the field are just nearby...But. I feel much safer playing indoors because I think my neighbourhood is not so safe. I heard about burglary cases in my neighbourhood. I'm scared of these bad people. (Translated by the author)

It is important for parents to assure children can have their own views on things and they can also express their views freely. The child will develop at an early age the sense that the environment is, in part, created by people including themselves. When parents are very concerned about their children's safety, it will affect the children's independent mobility and limit the allowable boundary for 
Mariatul Liza Meor Gheda \& Habizah Sheikh Ilmi

The Safe and Nurturing Living Environment for Urban Children

children to play in places away from home. Parents are concerned about the safety of their children (Veitch, 2005) which are mainly related to the danger of traffic, strangers and other nuisance (Veitch, 2005; Castonguay \& Jutras, 2010). In addition, when car becomes the most popular means for the children to go to school, the opportunity for them to visit local parks, engage in natural play in the surrounding neighbourhood area and ride their bikes or scooters in the streets in their free time are made limited. In fact, it appears that driving children to school is more about convenience rather than for safety purposes.

\section{Community Support}

The sense of community living is very important for the assurance that parents could trust others to observe their children and this 'others' are their neighbours. If the parents themselves do not have this sense of community support, the number of children using the outdoor spaces would decrease. Parents with a great sense of community will be more open to let their child use the shared outdoor spaces as compared to parents with a relatively lesser sense of community. As stated by Shamsuddin, Zaini andSulaiman (2014), parents who have a close relationship with their neighbours (whose children were their children's peers) do feel more confident to allow the children use the outdoor spaces without the parents' close supervision. The accessibility of children to their play space is also important to create a child friendly neighbourhood environment. Kytta (2004) stated that accessibility is the opportunity for children to be able to access their physical affordances.

The other issue is the case of missing children that make parents become suspicious of their children's surrounding. Therefore, it is the responsibility of every community member to be vigilant and informed about what is happening within the neighbourhood, so that should there be anything out of the ordinary, then the necessary actions such as alerting the police or other neighbours can be taken. Passive surveillance is also reduced by low sense and connection with the community. Thus, a strong sense of community among the residents could increase the sense of belonging amongst the community and to the place itself. Since most of the parents here may be living far from their relatives, therefore, the strong sense of community amongst the residents is very important. Having a loving family, caring and friendly neighbours are the greatest support in a child friendly neighbourhood environment. In overall, the finding shows that the significant features which can promote a safe and nurturing environment for children to roam around freely are positive parents and community support.

\section{CONCLUSION}

Everyone experiences fear at some points in their lives. Children, however, are particularly likely to have fears. Adults might see children's fears as silly but they are very real to the children. In this research, positive parents and community 
PLANNING MALAYSIA

Journal of the Malaysia Institute of Planners (2019)

support are the main characteristics to promote a safe and nurturing living environment for children. It is clear that the children who attended the participatory workshop implied that lack of space and the accessibility for ordinary surveillance should be measured. They wanted the play space as their meeting point for all children in the living area. Apart from that, children wanted also a place where they could create their own play opportunities while being safe.

\section{REFERENCES}

Adams, E. (2006). Drawing insights. London: The Campaign for Drawing.

Amstrong, D. (2000). A survey of community gardens in upstate New York: Implications for health promotion and community development. Health \& Place, 6(4), 31927.

Bell, J., Wilson, J. \& Liu, G. (2003). Neighborhood greenness and 2-year changes in body mass index of children and youth. American Journal of Preventive Medicine, 35(6), 547-553.

Bjorklid, P. \& Nordstrom, M. (2007). Environmental Child-Friendliness: Collaboration and Future Research. Children, Youth and Environments, 17(4), 388-401.

Bjorklid, P. \& Nordstrom, M. (2012). Child-friendly cities - sustainable cities. Early Childhood Matters, 118, 44-47.

Capon, A.G. \& Blakely, E.J. (2008). Checklist for Healthy and Sustainable Communities. Journal of Green Building. 3(2) 41-45

Carver, A., Timperio, A. \& Crawford, D. (2008). Playing it safe: The influence of neighborhood safety on children's physical activity. A review. Health \& Place, 14 (2), 217-227.

Castonguay, G. \& Jutras, S. (2010). Children's use of the outdoor environment in a low-income Montreal neighborhood. Children, Youth and Environments, 20(1), $200-230$

Chawla, L. (2002). Growing Up in an Urbanising World. London. UNESCO: Publising \& Earthscan Publications.

Day, K (1999). Strangers in the Night: Women's Fear of Sexual Assault on urban College Campuses. Journal of Architectural \& Planning Research, 16 (4) 289-312.

Donaldson, M. (1978). Children's Minds. Glasgow: Fontana Press

Elsley, S. (2004). Children's experiences of public space. Children \& Society, 18(2), 155164.

Foster S, Giles-Corti B \& Knuiman M (2010). Neighbourhood design and fear of crime: A social-ecological examination of the correlates of residents' fear in new suburban housing developments. Health Place

Foster, S., Wood, L., Francis, J., Knuiman, M., Villanueva, K. \& Giles-Corti, B. (2015). Suspicious minds: Can features of the local neighbourhood ease parents' fears about stranger danger? Journal of Environmental Psychology.

Freeman, C. \& Tranter, P. (2011). Children and their urban environment: changing worlds. London: Earthscan. 
Mariatul Liza Meor Gheda \& Habizah Sheikh Ilmi

The Safe and Nurturing Living Environment for Urban Children

Gleeson, B. \& Sipe, N. (2006). Creating Child Friendly Cities: Reinstating kids in the City. London: Routledge.

Hart, R. (1979). Children's Experience of Place. Newyork: Irvington.

Hillier, B. (2004). Can Streets Be Made Safe? Urban Design International, 9 (1): 31-45.

Jacobs, J. (1961). The Death and Life of Great American Cities. New York: Random House, Inc.

Jorgensen, L. J., Ellis, G. D. \& Ruddell, E. (2012). Fear perceptions in public parks: Interactions of environmental concealment, the presence of people recreating and gender. Environment and Behavior, 45 (7), 803- 820.

Kaboom. (2010). New York City: Streets Renaissance Campaign - Streets as Places to Play. New York: Kaboom.

Kytta, M. (2004). The extent of children's independent mobility and the number of actualized affordances as criteria for child-friendly environments. Journal of Environmental Psychology, 24 (2), 179-198

Malone, K (2013). "The future lies in our hands": children as researchers and environmental change agents in designing a child-friendly neighbourhood. The International Journal of Justice and Sustainability. 18 (3), 372-395

Marret, M. J., Satar, A. \& Ismail, Z. (2013). Keep Your Child Safe. Malaysia: The Star.

Maruthaveeran, S. \& Van den Bosch, C. C. K (2014). A Social-Ecological Exploration of Fear of Crime in Urban Green Spaces - A Systematic Review. Urban Forestry \& Urban Greening, 13 (1), 1-18

McAllister, C., Lewis, J. \& Murphy, S. (2012). The green grass grew all around: Rethinking urban natural spaces with children in mind. Children, Youth and Environments , 22 (2), 164-193.

Pucher, J., \& Dijkstra, L. (2003). Promoting safe walking and cycling to improve public health: lessons from The Netherlands and Germany. Am J Public Health, 93 (9), $1509-1516$.

Riggio, E. (2002). Child friendly cities: good governance in the best interests of the child. Environment and Urbanization, 14(2), 45-58

Rissotto, A. \& Tonucci, F. (2002). Freedom of Movement and Environmental Knowledge in Elementary School Children. Journal of Environmental Psychology, 22(1-2), $65-77$

Robinson, W. (1986). Children's Understanding of teh Distincion between Messages and Meaning: Emergence and Implications. In Richards, M. \& Light, P. (Eds). (1986). Worlds. Cambridge: Polity

Shamsuddin, S., Zaini, K., \& Sulaiman, A.B. (2014). . Effctiveness of Gated Communities in Providing Safe Environments for Children's Outdoor Use. Procedia - Social and Behavioral Sciences, 140, 77 - 85 .

Skar, M. \&Krogh, E. (2009). Changes in children's nature-based experiences near home: from spontaneous play to adult-controlled, planned and organised activities. Children's Geographies. 7(3), 339-354 Sutton, L. (2008). The State of Play: Disadvantage, Play and Children's Well-Being, Social Policy \& Society, 7(4), 537-549.

The Star. (2016). Nearly 4,000 Malaysian children went missing in 2014 and 2015. theStarOnline.

Retrieved

from 
https://www.thestar.com.my/news/nation/2016/03/24/nearly-4k-missingchildren-in-last-two-years/

Veitch, H. (2005). Evaluation report on children's participation at the East Asia Pacific Regional Consultation for the UN Study on Violence against Children,

Bangkok, UNVAC Regional Steering Committee.

Watson, M. \& Dannenberg, A. (2008). Investment in Safe Routes to School Projects: Public Health Benefits for the Larger Community. Preventing Chronic Disease, 5 (3), A90.

Received: $28^{\text {th }}$ October 2018. Accepted: $1^{\text {st }}$ March 2019 